\title{
A method for accurate measurements of the respiration rates of marine invertebrate embryos and larvae
}

\author{
Adam G. Marsh*, Donal T. Manahan \\ Department of Biological Sciences, University of Southern California, Los Angeles, California 90089-0371, USA
}

\begin{abstract}
Measurements of respiration rates are essential to quantify the energy requirements of embryos and larvae. Here we describe a ' $\mu$ BOD' method that employs small $(<1 \mathrm{ml})$ Biological Oxygen Demand (BOD) glass vials in which embryos and larvae are incubated. A decrease in oxygen concentration is measured by injecting seawater from each vial into the measurement chamber of a standard polarographic oxygen sensor. This $\mu B O D$ method was used to measure respiration rates of larvae of the sea urchin Strongylocentrotus purpuratus (at $15^{\circ} \mathrm{C}$ ) and embryos and larvae of 2 Antarctic echinoderms, the sea urchin Sterechinus neumayeri and the seastar Odontaster validus (both at $-1.5^{\circ} \mathrm{C}$ ). For validation, a comparison of different methods was performed with embryos and larvae of $S$. neumayeri. The $\mu \mathrm{BOD}$ method gave results for respiration rates during development that were equivalent to those obtained with either coulometric capacitance respirometry or standard Winkler's titrations of large $(300 \mathrm{ml}) \mathrm{BOD}$ bottles. Currently, the most common method for measuring respiration rates of invertebrate embryos and larvae is to place them in small respiration chambers and continuously monitor oxygen tension with a polarographic oxygen sensor (POS). However, respiration rates for embryos and larvae of $S$. neumayeri were underestimated when standard POS measurements were compared to the measurements made with either $\mu B O D$, Winkler's titrations or coulometric capacitance respirometry. A comparison of the $\mu B O D$ and POS methods during early development in $S$. neumayeri resulted in different estimates of 920 and $343 \mu \mathrm{J}$, respectively, for the total energetic cost of embryogenesis to gastrulation, illustrating that the POS error can be as great as $63 \%$. The $\mu$ BOD method is accurate for micro-respiration measurements of invertebrate embryos and larvae as well as being simple to operate and appropriate for field work.
\end{abstract}

KEY WORDS: Embryos - Larvae - Respiration - Development - Sterechinus neumayeri - Odontaster validus

\section{INTRODUCTION}

One of the key components to establishing the energy requirements for embryonic and larval development is an accurate measure of respiration rate. Although several methods have been developed to measure respiration rates of embryos and larvae, most of them are not routinely used. Meyer (1935) adapted a micro-scale, Winkler's titration for use with echinoderm larvae and Zeuthen (1943) developed a microCartesian diver appropriate for single polychaete

•E-mail:amarsh@usc.edu embryos. Subsequent work by Scholander et al. (1952) used micro-Cartesian divers for single embryo measurements and, for a study of barnacle larvae, Bhatnagar \& Crisp (1965) used a micro-Winkler technique with gas-tight syringes. Further details of some earlier approaches to measuring larval respiration rates are reviewed by Crisp (1974).

Since then, other methods for measuring oxygen consumption have been developed for invertebrate larvae. In particular, the use of a polarographic oxygen sensor (POS) to continuously detect the rate of oxygen consumption in small, sealed chambers has become the most commonly used method to measure larval respiration (Gerdes 1983, Gnaiger 1983, Manahan 
1983). Recently, however, doubts concerning the accuracy of POS/micro-respiration chambers have been raised. When comparisons were made of respiration rates obtained by coulometric capacitance respirometry. Winkler's titrations, and POS/micro-respiration chambers, the latter method underestimated larval respiration by up to 3-fold (Hoegh-Guldberg \& Manahan 1995, Shilling et al. 1996). Although environmental detection by an oxygen sensor is accurate and the use of POS in closed-volume micro-respiration applications can be reliable for some species (e.g. Artemia sp.: Hoegh-Guldberg \& Manahan 1995), the broad use of this method with embryos and larvae is suspect. On the other hand, while techniques such as micro-Cartesian divers and coulometric capacitance respirometry are accurate, they have the limitation that they are technically complex and difficult to use. Thus, despite the development of many different methods and increased technical sophistication, respiration rates of developmental stages still remain problematic to measure.

In larval biology, there is a need for a method to measure oxygen consumption rates that: (a) is accurate in measuring respiration rates (as micro-Cartesian divers or coulometric capacitance respirometry), (b) is robust enough to be easily used in the field (as Biological Oxygen Demand [BOD] bottles), and (C) is methodologically simple to use (as POS). In this paper we describe a method that combines the use of small BOD vials with an end-point detection using POS. This approach measures embryonic and larval respiration rates with the accuracy of both coulometric capacitance respirometry and Winkler's titrations but offers the advantage of allowing for a large number of samples to be quickly measured.

\section{MATERIALS AND METHODS}

Embryonic and larval culture. In California, adult sea urchins Strongylocentrotus purpuratus were purchased from Marinus Inc, Long Beach, and used within $24 \mathrm{~h}$ for spawning. In Antarctica, adult sea urchins Sterechinus neumayeri and seastars Odontaster validus were collected by SCUBA divers from McMurdo Sound (off Cape Evans and the Delbridge Islands) during austral spring. These animals were maintained at constant temperature $\left(-1.5^{\circ} \mathrm{C}\right)$ in $500 \mathrm{I}$ runningseawater tanks at McMurdo station until they were needed for spawning.

For the sea urchins, gametes were obtained by intracoelomic injections of $0.5 \mathrm{M} \mathrm{KCl}$. For the Antarctic seastar Odontaster validus, gametes were obtained by injections of $10 \mathrm{mM}$ 1-methyladenine. Eggs were pooled from several females for fertilization by sperm from 1 male. Once fertilization was verified to be greater than $90 \%$ (elevation of fertilization envelope), the fertilized eggs were transferred to either $20 \mathrm{l}$ or 2001 culture containers at concentrations of 7 to 20 ind. $\mathrm{ml}^{1}$. For cultures of Strongylocentrotus purpuratus, the culture temperature was maintained at $15^{\circ} \mathrm{C}$ in a walk-in environmental room. For the Antarctic echinoderms, the culture temperature was maintained at $-1.5^{\circ} \mathrm{C}$ by immersing the containers in large flowthrough tanks $(1000 \mathrm{l})$ that had a high flow of ambienttemperature seawater pumped directly from McMurdo Sound. During development, embryos and larvae were kept in suspension by gently mixing ( 5 to $10 \mathrm{rpm}$ ) the cultures with rotating paddles in the $20 \mathrm{l}$ containers, or vertical-plunging paddles in the $200 \mathrm{l}$ containers. When changing the culture water levery $4 \mathrm{~d}$ for the Antarctic species), all individuals were removed from their respective containers by sieving onto an $80 \mu \mathrm{m}$ mesh screen. The culture container was then cleaned, new filtered $(0.20 \mu \mathrm{m}$ pore-size) seawater was added and, after enumeration for sampling, the embryos or larvae were replaced

Respiration measurements with $\mu$ BOD vials. Microscale Biological Oxygen Demand $(\mu B O D)$ vials were custom-made using $6 \mathrm{~mm}$ (i.d.) by $2.5 \mathrm{~cm}$ long glass test tubes joined to $7 / 25$ tapered ground-glass stopcocks. The volume of each vial was determmed individually (range for 30 vials was 854 to $1012 \mu l$ ). Developing embryos and larvae were transferred in sterile-filtered seawater to the $\mu \mathrm{BOD}$ vials to give a final concentration that ranged from 16 to 669 ind. vial $^{-1}$ for Strongylocentrotus purpuratus, 87 to 494 ind. vial $^{-1}$ for Sterechinus neumayeri, and 25 to 626 ind. vial $^{-1}$ for Odontaster validus. Several vials without animals were also prepared for each set of measurements to control for background consumption of oxygen. These 'blank' rates were subtracted from the experimental rates before any further data analysis. The $\mu B O D$ vials were incubated horizontally to prevent the non-swimming stages from accumulating in a small volume at the bottom of the vial. The incubation time at the appropriate culture temperatures was selected to be sufficient to produce a measurable drop in oxygen concentration. Depending on developmental stage, the incubation times ranged from 8 to $12 \mathrm{~h}$ for $S$. neumayeri and $O$. validus at $-1.5^{\circ} \mathrm{C}$, and $4 \mathrm{~h}$ for $S$. purpuratus at $15^{\circ} \mathrm{C}$. After calibration of the POS with standards, the final oxygen concentration in each vial was determined by injecting a sub-sample into a micro-respiration chamber for an end-point measurement by POS (see below).

End-point measurement of oxygen by POS. Oxygen concentrations in sub-samples that were taken from the $\mu B O D$ vials at the end of the incubation period were measured with a POS (Model 1302, Strathkelvin) connected to an oxygen meter (Model 928, Strath- 
kelvin). The meter was set to 0 by placing the electrode in a borate buffer deoxygenated by the addition of sodium sulfite (according to the manufacturer's instructions) and by unplugging the electrode for a 0 signal. The most critical aspect of the calibration was the setting of the high-end of the meter scale. Both of the low-end settings above produced an equivalent response when the full-scale reading on the meter was set to an oxygen saturated seawater standard equilibrated at the appropriate temperature. Actual oxygen concentrations were confirmed chemically by Winkler's titrations thereby verifying the level of saturation. The oxygen saturated solution was injected into the POS electrode housing and the meter scale slightly adjusted until 2 consecutive measurements were equivalent to the saturation value $( \pm 1 \mu \mathrm{M})$ of $361 \mu \mathrm{M}$ at $-1.5^{\circ} \mathrm{C}$ and $255 \mu \mathrm{M}$ at $15^{\circ} \mathrm{C}$ (at $34 \%$ S). After the POS was calibrated, another oxygen saturated sample was injected to measure the amount of time required for the POS response to stabilize (usually $5 \mathrm{~min}$ at $-1.5^{\circ} \mathrm{C}$ and $3 \mathrm{~min}$ at $15^{\circ} \mathrm{C}$ ) and this time interval was used for all subsequent readings of experimental samples.

Data recording and analysis were done with a laptop computer using the manufacturer's software. Two respiration chambers (RC-200) were used simultaneously with the volume of each set at $75 \mu$ l. The temperature of the electrode was maintained by a refrigerated water bath $\left( \pm 0.02^{\circ} \mathrm{C}\right)$ connected to the thermal jacket of each respiration chamber. Just prior to measuring the oxygen concentration, each $\mu \mathrm{BOD}$ vial was placed in a hand centrifuge to pellet the embryos or larvae. They were then quickly removed from the bottom of the vial for later enumeration. A temperature-equilibrated, glass gas-tight syringe (250 $\mathrm{\mu l}$ total volume; capillary stainless-steel needle with $5 \mu$ d dead-volume, Unimetrics Corp) was used to withdraw $200 \mu$ laliquots from each vial for immediate injection into the POS. These samples were injected into a $75 \mu$ respiration chamber for end-point determinations of oxygen concentration. The central vent-port of the RC-200 chamber had the appropriate diameter for the syringe needle. For each measurement, two $200 \mu$ l samples were injected to insure that the chamber was fully purged of the previous sample $(400 \mu \mathrm{l}$ total $=$ ca 5 times the chamber volume). In preliminary experiments, adequate purging was determined by injecting deoxygenated seawater into the respiration chamber and then noting the volume of saturated seawater that was necessary to purge the deoxygenated water.

By directly injecting the samples into the respiration chamber, the membrane of the POS was continuously maintained at the required temperature between samples. This protocol reduced the sensor equilibration time normally necessary when a membrane is exposed to air at room temperature while animals are added or removed from the chamber during normal POS operation (2 to $3 \mathrm{~h}$ to re-equilibrate at $-1.5^{\circ} \mathrm{C}$, Shilling \& Manahan 1994). In our application, the POS and microrespiration chamber were used as a 'blood gas' analyzer for sample injections, in contrast to the more common use of this instrumentation where decreases in oxygen concentration are continuously monitored in the presence of developing embryos and larvae. This latter 'standard' method was also included in our comparison of methods (see below).

Continuous measurement of respiration using a POS. Respiration rates of embryos and larvae of Sterechinus neumayeri were measured in POS/microrespiration chambers as described above (RC-200). When the chamber volume was set at $100 \mu \mathrm{l}$, a stable background reading was recorded for filtered seawater at $-1.5^{\circ} \mathrm{C}$ after 2 to $3 \mathrm{~h}$. Once a linear background rate was obtained, the chamber tops were removed and 50 to 100 ind. were placed into the respiration chamber. Typically, after a 2 to $3 \mathrm{~h}$ stabilization period, oxygen consumption was linear and measurements were then continuously recorded for 4 to $6 \mathrm{~h}$ for developing stages of $S$. neumayeri. Controls for background oxygen consumption in the absence of animals and for sensor drift were conducted for the same amount of time both before and after each experiment with animals present (blank $\rightarrow$ animals $\rightarrow$ blank). All experimental measurements were corrected for background oxygen consumption rates that never exceeded $10 \%$ of animal respiration rates. No detectable sensor drift occurred during a set of measurements. Sensor response at low temperatures $\left(-2^{\circ} \mathrm{C}\right)$ to changes in oxygen concentrations in seawater were previously validated by Winkler's titrations (Shilling \& Manahan 1994).

Respiration measurements with $300 \mathrm{ml}$ BOD bottles. For comparison to the respiration rates obtained using the $\mu B O D$ vials, a series of Winkler's chemical titrations (Parsons et al. 1984) was run in $300 \mathrm{ml}$ BOD bottles (abbreviated ' $m B O D$ ' in the 'Figures' for macro-BOD bottle). The BOD bottles were run in triplicate and incubated for $24 \mathrm{~h}$ at $-1.5^{\circ} \mathrm{C}$ with 30000 ind bottle ${ }^{-1}$. Control BOD bottles with no animals present were also run to correct for any background consumption of oxygen. In addition to chemically determining the oxygen concentrations in the BOD bottles after the incubation period, $1 \mathrm{ml}$ aliquots were removed prior to chemical fixation and transferred to $\mu \mathrm{BOD}$ vials for immediate end-point measurements by POS (as described above). These measurements served as handling controls for the syringe transfer of samples from the $\mu \mathrm{BOD}$ vials to the POS. These controls were examined for any possible losses or gains of oxygen during syringe transfer and injections (none occurred).

Coulometric capacitance respirometry. This method establishes an oxygen chemostat in a sealed micro- 
respiration chamber into which molecular oxygen is released from the electrolysis of water (Huesner et al. 1982). The rate of oxygen replacement is quantified by the amount of current required for oxygen regeneration (Hoegh-Guldberg \& Manahan 1995), which is a measure of the oxygen consumed by the organisms in the sealed respiration chamber. A custom-built solidstate current generator and metering device was designed for our purposes by Energy Exchange Inc (Winters, CA). For this study with embryos and larvae of Sterechinus neumayeri, the glass respiration chambers were modified from Huesner \& Tracy (1984) to provide a chamber capable of holding $1.5 \mathrm{ml}$ of seawater with a minimal air volume designed from the larger chambers used by Hoegh-Guldberg \& Manahan (1995). A personal computer was connected to the current device for data recording in a format that could later be imported into a standard spreadsheet program. At McMurdo Station, the respirometry equipment was placed in a $-7^{\circ} \mathrm{C}$ walk-in environmental room with an antagonistic submersion heater and circulator (Haake Model N-3) in a 40 I water bath surrounding the respiration chambers. During measurements, the temperature was maintained at $-1.5^{\circ} \mathrm{C}$ $\left( \pm 0.01^{\circ} \mathrm{C}\right)$. All respiration chamber components and solutions were allowed to equilibrate for $4 \mathrm{~h}$ before animals were loaded into them. After animals were put into the chambers, an additional equilibration period of 2 to $4 \mathrm{~h}$ passed before the chambers were barometrically sealed and the internal anode was set to record. Recordings of respiration rates were made continuously over 10 to $20 \mathrm{~min}$ intervals for a duration of 1 to $2 \mathrm{~d}$ (midpoints of the tracings of coulometric respirometry in the 'Results' section correspond to the midpoint times of incubation of the other methods tested for comparisons of respiration rates).

Statistical computations. All of the statistical analyses and confidence intervals on regressions were computed by the SigmaStat 2.0 program (Jandel Scientific Software). For the comparison among the different respiration methods, 1-way ANOVA was used to detect differences in respiration rates due to methods and Tukey's multiple range tests were used to identify which methods gave significantly different measurements of respiration rates. When sample variances were not normally distributed, the analyses used a non-parametric Kruskal-Wallis ANOVA on ranks with Dunn's multiple range test to identify significant differences.

\section{RESULTS}

Fig. 1 shows the output signal from a POS for a series of injections of subsamples from $\mu \mathrm{BOD}$ vials. An air-

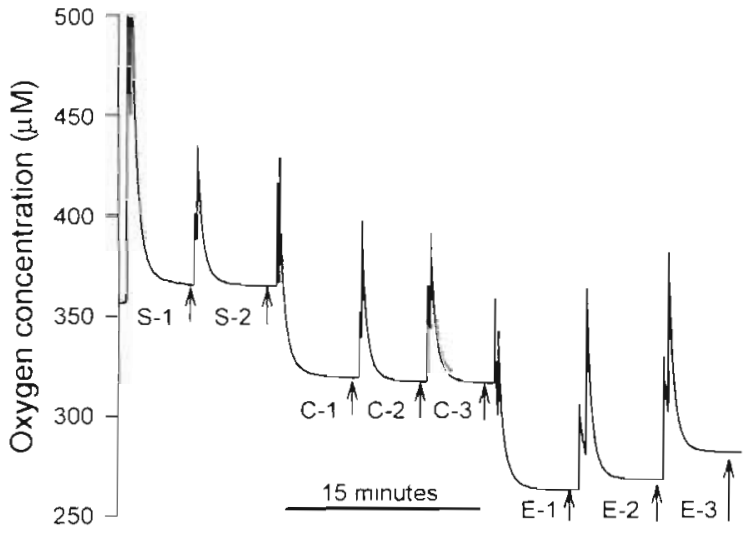

Fig. 1. The $\mu \mathrm{BOD}$ method. Plot showing recordings from an oxygen meter (Strathkelvin 928) of serially injected seawater samples taken from $1 \mathrm{ml} \mu \mathrm{BOD}$ vials. After injection of $2 \times$ $200 \mu \mathrm{l}$ of seawater from each sample vial into the sample chamber, a reading of the oxygen concentration of the sample was taken after the polarographic oxygen sensor had stabilized. Tracings labeled as S-1 and S-2 represent seawater standards of known oxygen concentration $(361 \mu \mathrm{M})$ to calibrate the instrument at $-1.5^{\circ} \mathrm{C}$. Tracings labeled as $\mathrm{C}-1, \mathrm{C}-2$ and $\mathrm{C}-3$ are control samples (no embryos present) from $\mu B O D$ vials that were incubated for the same duration as the experimental vials. Different numbers of embryos of the Antarctic sea urchin Sterechinus neumayeri (labeled as E-1, E-2, E-3) had been incubated at $-1.5^{\circ} \mathrm{C}$ in each vial and resulted in correspondingly different end-point oxygen concentrations for E-1 to E-3. Arrows were placed at the sampling time interval determined during meter calibration to give stable readings

saturated, filtered seawater standard (concentration verified by Winkler's titrations) was injected twice to calibrate the meter to the POS output signal (labeled S-1, S-2), followed by 3 control $\mu B O D$ vials (incubated with no larvae: C-1,C-2, C-3) and 3 experimental $\mu B O D$ vials (each incubated with different numbers of larvae: E-1, E-2, E-3). The continuous plot of the sensor's response shows several aspects of the analysis. First, sample equilibration of the POS occurred within $5 \mathrm{~min}$ after each set of two $200 \mu \mathrm{l}$ injections, even at $-1.5^{\circ} \mathrm{C}$. Second, the reproducibility of the measurements is evident in the consistent response between the 2 standards (difference $=0.09 \%$ ) and 3 controls (maximum difference $=0.11 \%)$. Third, samples can be processed continuously so that the total assay time for $24 \mu \mathrm{BOD}$ vials was less than $2 \mathrm{~h}$.

Concentration-dependent interactions are a major concern with any method that measures respiration rates from a population of animals in small volumes. A series of $\mu B O D$ vials were loaded with $3 \mathrm{~d}$ old prismstage embryos of the sea urchin Strongylocentrotus purpuratus with a range of 16 to $669 \mathrm{ind}^{-v_{\text {val }}{ }^{-1}}$ (Fig. 2A). The respiration rates were linear over this wide range of concentrations, with an individual respiration rate of 

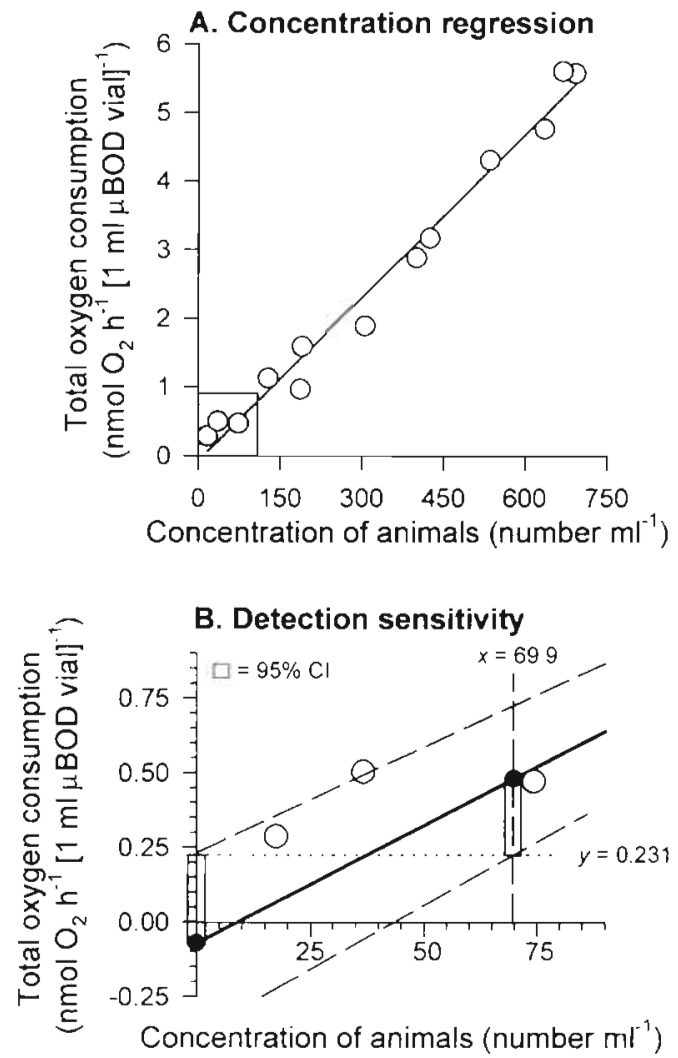

Fig. 2. Total oxygen consumed in $\mu B O D$ vials with 3 d old prism-stage embryos of the sea urchin Strongylocentrotus purpuratus (at $15^{\circ} \mathrm{C}$ ). Each point is a single sample taken from a different $\mu B O D$ vial and all vials were incubated in parallel. (A) The slope of the line is the ratio between oxygen consumption rate and number of embryos, giving a respiration

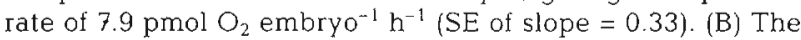
region outlined by the gray box in $(A)$ is expanded with the $95 \%$ confidence interval of the regression (plotted as dashed lines). The regression sensitivity of the $\mu B O D$ method is calculated from the upper $95 \%$ confidence interval of the $y$-intercept $(\bullet-0.072+0.303=0.231)$. At $x>69.9$ animals $\mathrm{ml}^{-1}$ the respiration rate of the regression function $(\bullet ; 0.482 \pm 0.251 \mathrm{nmol}$

$\mathrm{O}_{2} \mathrm{~h}^{-1}$ ) was significantly greater than the $y$-intercept

$7.9 \mathrm{pmol} \mathrm{O}_{2}$ embryo $^{-1} \mathrm{~h}^{-1}$ as determined by the slope of a regression line ( $\mathrm{SE}$ of slope $=0.33, \mathrm{n}=13, \mathrm{r}^{2}=0.981$ ) The $y$-intercept is not significantly different from zero ( $t$-test $y=0, p=0.608)$. The respiration rate of prisms was not affected at concentrations below $700 \mathrm{ml}^{-1}$ in the $\mu B O D$ vials. Fig. $2 B$ expands the graph at the intercept to show the $95 \%$ confidence intervals used to calculate the sensitivity of the regression method (see below). The confidence intervals shown are curvilinear as calculated by the SigmaStat 2.0 software package, but they appear linear because the $x$-axis range is small and the variance of the regression estimates was low.

During development, ontogenetic changes in concentration-dependent effects on respiration may occur. We examined several developmental stages of 2 Ant- arctic echinoderms to determine if the $\mu B O D$ method was appropriate for embryonic and larval stages that have low respiration rates at $-1.5^{\circ} \mathrm{C}$. For the seastar Odontaster validus, 3 to $4 \mathrm{~d}$ old embryos, $7 \mathrm{~d}$ old blastulae, $15 \mathrm{~d}$ old gastrulae and $25 \mathrm{~d}$ old bipinnaria stages of development were used to measure respiration rates as a function of changing the concentration of animals (Fig. 3). Over a wide range of concentrations (20 to 600 ind $\mathrm{ml}^{-1}$ ), total respiration remained a linear function of the number of individuals per vial for the 4 stages examined. Significant increases in respiration. during development were evident as calculated from regression slopes $( \pm \mathrm{SE})$, from a low of $4.4 \pm 0.18 \mathrm{pmol}$ $\mathrm{O}_{2}$ embryo $^{-1} \mathrm{~h}^{-1}\left(\mathrm{r}^{2}=0.953 ; \mathrm{n}=30\right), 5.5 \pm 0.27 \mathrm{pmol} \mathrm{O}_{2}$ blastula $^{-1} \mathrm{~h}^{-1}\left(\mathrm{r}^{2}=0.953 ; \mathrm{n}=22\right),, 11.3 \pm 0.45 \mathrm{pmol}_{2}$ gastrula $^{-1} \mathrm{~h}^{-1}\left(\mathrm{r}^{2}=0.950 ; \mathrm{n}=36\right)$, to a high of $13.0 \pm$ $0.48 \mathrm{pmol}_{2}$ bipinnaria $^{-1} \mathrm{~h}^{-1}\left(\mathrm{r}^{2}=0.945 ; \mathrm{n}=44\right)$. The regressions presented for blastula, gastrula and bipinnaria stages have $y$-intercepts that are statistically different from zero ( $t$-test for $y=0 ; p=0.002, p<0.001$ and $p<0.001$, respectively). The $y$-intercept of the 3 to $4 \mathrm{~d}$ old embryos is not statistically different from zero ( $t$-test for $y=0 ; p=0.981)$. The significance of the $y$-axis intercepts has important implications for the sensitivity of micro-respiration measurements (see 'Discussion').

Similar measurements were made to test possible concentration-dependent effects on respiration in $\mu \mathrm{BOD}$

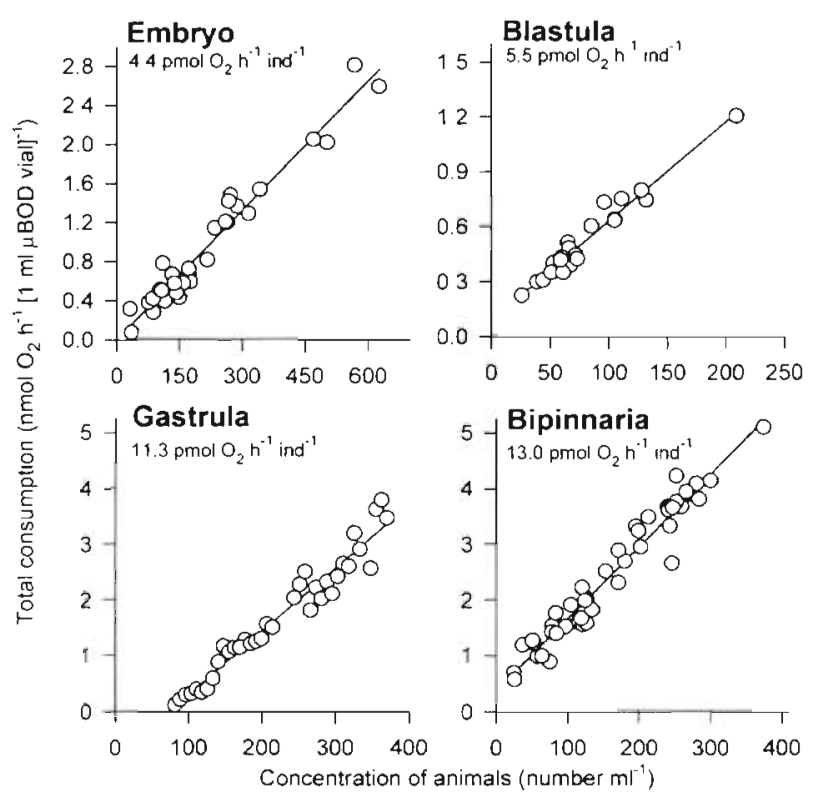

Fig. 3. Total oxygen consumed at $-1.5^{\circ} \mathrm{C}$ in $\mu \mathrm{BOD}$ vials containing developing stages of the Antarctic seastar Odontaster validus as a function of different concentrations of individuals in each vial. Individual respiration rates (pmol $\mathrm{O}_{2}$ ind. $^{-1} \mathrm{~h}^{-1}$ ) were calculated as the slope of the regression between total oxygen consumption rate and total number of individuals for each of 4 developmental stages 
vials for 2 to $3 \mathrm{~d}$ old embryos, $6 \mathrm{~d}$ old blastulae, $11 \mathrm{~d}$ old gastrulae and $18 \mathrm{~d}$ old prism stages of development of the Antarctic sea urchin, Sterechinus neumayeri (Fig. 4). As with Strongylocentrotus purpuratus and Odontaster validus, respiration was linear over a wide range of individual concentrations (100 to 500 ind $\mathrm{ml}^{-1}$ ). No concentration-dependent inhibition of respiration was apparent in $S$. neumayeri until concentrations exceeded 600 ind. $\mathrm{ml}^{-1}$ in the $\mu \mathrm{BOD}$ vials (data not shown). Significant increases in respiration (pmol $\mathrm{O}_{2}$ embryo ${ }^{-1} \mathrm{~h}^{-1} ; \pm \mathrm{SE}$ ) during development were evident, from a low in embryos of $2.4 \pm 0.48\left(\mathrm{r}^{2}=0.511 ; \mathrm{n}=\right.$ $26)$, to $5.4 \pm 0.61$ in blastulae $\left(r^{2}=0.763 ; n=26\right)$, to $10.2 \pm 0.12$ in gastrulae $\left(\mathrm{r}^{2}=0.799 ; \mathrm{n}=21\right)$, and to $\mathrm{a}$ high of $14.4 \pm 0.11$ in prism stages $\left(\mathrm{r}^{2}=0.868 ; \mathrm{n}=27\right)$. The regressions presented for embryonic and blastula stages have $y$-intercepts that are statistically different from zero ( $t$-test for $y=0, p<0.001$ and $p<0.01$, respectively), while the $y$-intercepts of the gastrula and prism stage regressions are not statistically different from zero ( $t$-test for $y=0, p<0.252$ and $p<0.822$, respectivelyj.

Another important issue for respiration measurements of embryos and larvae is the sensitivity of a method. This is usually defined as the minimum statistically significant change in oxygen concentration that can be detected above the background removal of oxygen present in any experimental system. In a linear

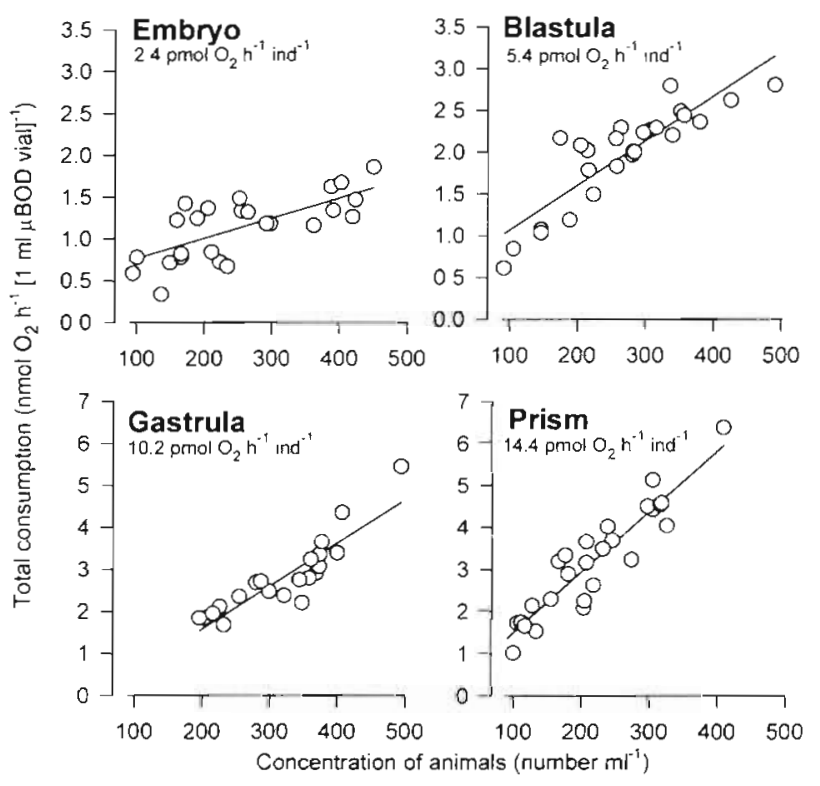

Fig. 4. Total oxygen consumed at $-1.5^{\circ} \mathrm{C}$ in $\mu \mathrm{BOD}$ vials containing developing stages of the Antarctic sea urchin Sterechinus neumayeri as a function of different concentrations of individuals in each vial. Individual respiration rates (pmol $\mathrm{O}_{2}$ ind..$^{-1} \mathrm{~h}^{-1}$ ) were calculated as the slope of the regression between total oxygen consumption rate and total number of individuals for each of 4 developmental stages regression analysis of total oxygen consumption and total individuals (Fig. 2A), the background depletion of oxygen is best quantified as the regression's $y$-intercept because this value represents the amount of oxygen removal in the experimental samples with no animals. Theoretically, the $y$-intercept should be 0 after the oxygen consumption rates of the samples with animals have been corrected by the oxygen depletion present in samples without animals (blank controls); however, in micro-respirometry this is not always the case. In this context, the detection limit of the $\mu B O D$ method was assessed as the point where the total oxygen consumption from the regression function was significantly different from the regression's $y$-intercept, as estimated by $95 \%$ confidence intervals (Cls).

When $95 \%$ CIs were calculated for the regressions of oxygen consumption on concentration of animals (Figs. 2 to 4 ), the points where the upper 95\% CIs intercept the $y$-axis represent the $95 \%$ upper limit of the background depletion rate. For example, the respiration regression for prism-stage embryos of Strongylocentrotus purpuratus (Fig. 2B) has a $y$-intercept not statistically different from 0 of $-0.072 \pm 0.303 \mathrm{nmol} \mathrm{O}_{2}$ $\mathrm{h}^{-1}( \pm 95 \% \mathrm{CI})$ so that the upper $95 \%$ confidence limit of the $y$-intercept is $y=0.231 \mathrm{nmol} \mathrm{O} \mathrm{h}^{-1}$. The regression function is significantly greater than this $y$-intercept confidence interval at the point where the regression's lower $95 \% \mathrm{CI}$ is greater than 0.231 , which occurs at $x>69.9$ animals $\mathrm{ml}^{-1}$ (Fig. 2B). At this point, the estimated oxygen consumption rate from the regression line is $0.482 \pm 0.251 \mathrm{nmol} \mathrm{O} \mathrm{h}^{-1}\left( \pm 95 \% \mathrm{Cl}_{\text {i }}\right.$ range 0.231 to 0.733$)$. This value is the minimum regression point that is statistically greater than the background depletion rate of oxygen ( $y$-intercept $\pm 95 \% \mathrm{CI}$ ). In terms of oxygen concentrations, a decline of $0.482 \mathrm{nmol}$ in $1 \mathrm{ml}$ is a net change of $0.482 \mu \mathrm{M} \mathrm{O}_{2} \mathrm{~h}^{-1}$, which represents a statistically significant change of $0.8 \%$ over 4 h relative to a $255 \mu \mathrm{M} \mathrm{O}_{2}$ initial concentration (i.e. the oxygensaturation value at $34 \%$ salinity and $15^{\circ} \mathrm{C}$ ). In a similar fashion, the lower limits for the Antarctic echinoderms ranged from 0.170 to $0.724 \mu \mathrm{M} \mathrm{O}_{2} \mathrm{~h}^{-1}$ for Odontaster validus (Fig. 3) and from 0.966 to $1.127 \mu \mathrm{M} \mathrm{O}_{2} \mathrm{~h}^{-1}$ for Sterechinus neunayeri (Fig. 4), and represent a statıstically detectable change in oxygen concentrations of 0.4 to $2.4 \%$ over $8 \mathrm{~h}$ relative to a $361 \mu \mathrm{M} \mathrm{O}_{2}$ initial concentration (saturation at $34 \%$ and $-1.5^{\circ} \mathrm{C}$ ). However, these lower limits of the regression analyses do not represent an appropriate animal concentration for single, routine measurements because they are calculated from a high number of observations distributed over a wide range of animal concentrations (Fig. 2A: 16 to $669 \mathrm{ml}^{-1}$ ). For accurate measurements of respiration rates, different concentrations of animals need to be used over the concentration range known to be linear for the species under study. 
An important aspect of any method for measuring respiration rates is accuracy. For larvae of Sterechinus neumayeri, the accuracy of the $\mu B O D$ method was assessed by simultaneous comparisons with 4 other methods (Fig. 5). Method 1: larvae were placed directly into a $100 \mu$ respiration chamber ( $\mathrm{RC}-200$ ) for continuous measurements of $\mathrm{O}_{2}$ made with the POS over an $8 \mathrm{~h}$ period (Fig. 5; histogram labeled as POS); Method 2: measurements made with the $\mu B O D$ method (labeled as $\mu \mathrm{BOD}$ ); Method 3: larvae were placed in $300 \mathrm{ml}$ BOD bottles and after a $24 \mathrm{~h}$ incubation, 2 aliquots of $200 \mu$ l of seawater from each BOD bottle (identical to the way the $\mu B O D$ vials were sampled) were injected into the POS/micro-respiration chamber for an end-point measurement (labeled as mBOD); Method 4: Winkler's chemical titrations were immediately performed on the same $300 \mathrm{ml}$ BOD bottles (labeled as 'Winkler'); and Method 5: larval respiration rates were measured with coulometric capaci-

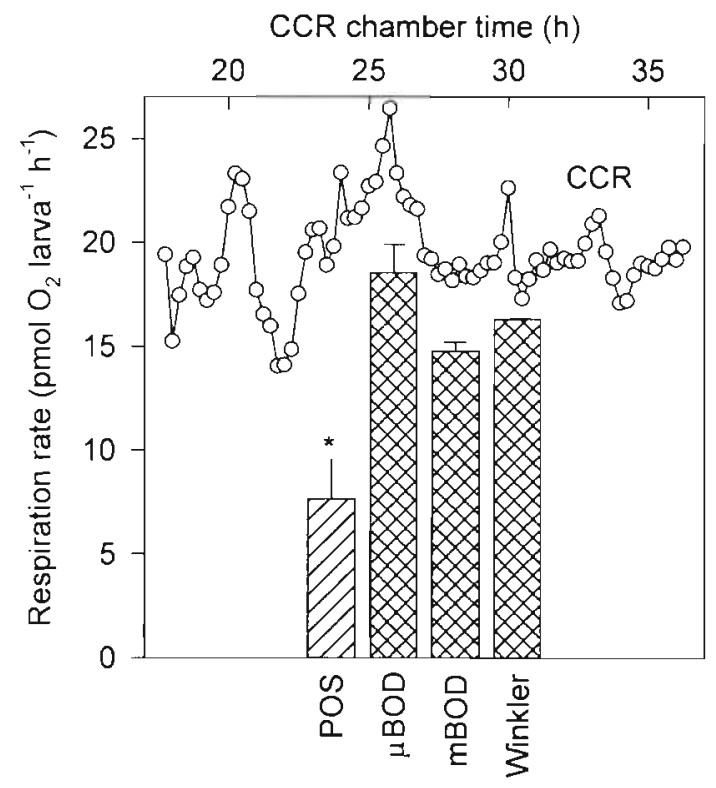

Fig, 5. Respiration rates at $-1.5^{\circ} \mathrm{C}$ of pluteus larvae of the Antarctic sea urchin Sterechinus neumayeri measured by 5 different methods: CCR: coulometric capacitance respirometry with the continuous $20 \mathrm{~h}$ duration of measurement plotted on upper $x$-axis; POS: continuous detection of respiration rate by a polarographic oxygen sensor in a $100 \mu \mathrm{l}$ microrespiration chamber $(n=2) ; \mu B O D$ : end-point determination of oxygen in a series of small $(<1 \mathrm{ml})$ BOD vials $(\mathrm{n}=3)$; MBOD: end-point detection by POS of oxygen in a series of large $(300 \mathrm{ml}) \mathrm{BOD}$ bottles $(\mathrm{n}=3)$; Winkler: direct chemical titration of dissolved oxygen in a series of large $(300 \mathrm{ml}) \mathrm{BOD}$ bottles ( $\mathrm{n}=3$; same ones subsampled for ' $m B O D$ ' above). Histograms are plotted as means $\pm 1 \mathrm{SE}$, except for the POS data where the uncapped vertical line represents the maximum value of the 2 replicate mesurements. Bars with the same shading are not statistically different, i.e. POS is different at $\mathrm{p}<0.05\left({ }^{\circ}\right)$ from $\mu \mathrm{BOD}, \mathrm{mBOD}$ and Winkler. The error bar of the Winkler analysis falls within the graphical representation of the histogram tance respirometry (tracing labeled as CCR). The measurements of larval respiration rates of $S$. neumayeri were not statistically different among the $\mu B O D$, $\mathrm{mBOD}$, and Winkler methods (ANOVA, Tukey's minimum significant range test, $\alpha=0.05$ ). However, these respiration rates $\left(\mu \mathrm{BOD}: 18.5 \mathrm{pmol} \mathrm{O}_{2} \operatorname{larva}^{-1} \mathrm{~h}^{-1}\right.$, mBOD: 14.8, and Winkler: 16.3) were all significantly greater than the respiration rate of $7.6 \mathrm{pmol} \mathrm{O}_{2}$ larva $^{-1}$ $\mathrm{h}^{-1}$ determined by continuous POS measurements (ANOVA, Tukey's minimum significant range test at $p<0.05$ ). When measured continuously with coulometric capacitance respirometry, the larval respiration rates of $S$. neumayeri varied over $20 \mathrm{~h}$ between 14.1 and $26.4 \mathrm{pmol} \mathrm{O}_{2}$ larva $^{-1} \mathrm{~h}^{-1}$, with a mean rate of $19.4 \mathrm{pmol} \mathrm{O}_{2}$ larva $^{-1} \mathrm{~h}^{-1}$ (Fig. 5, upper tracing). The CCR trace demonstrates the time-resolution for small changes in respiration rate during the course of the measurement $(20 \mathrm{~h})$, in contrast to the single end-point measurements of the other methods. The range of values from the CCR method falls within the endpoint, time-averaged, rates that were determined by the BOD bottle methods (Winkler's titrations and POS detection of water from the $300 \mathrm{ml} \mathrm{BOD} \mathrm{bottles)} \mathrm{and}$ the $\mu \mathrm{BOD}$ method, but are higher than the continuous POS readings.

This comparison of methods for measuring respiration of larval forms was extended to 4 earlier stages of development of Sterechinus neumayeri: $2 \mathrm{~d}$ old morula, $10 \mathrm{~d}$ old mid-gastrula, $15 \mathrm{~d}$ old late-gastrula and 19 d old prism stage (Fig. 6). Although not all of the methods were tested for each stage, the same comparative patterns found with the pluteus larvae (Fig. 5) were evident for earlier stages of development. In Fig. 6 the following findings are illustrated (with the statistical tests summarized below): (1) Winkler's titrations of $300 \mathrm{ml} \mathrm{BOD}$ bottles were not different from the respiration rates determined by directly injecting aliquots from the same BOD $300 \mathrm{ml}$ bottles into the POS chambers ('W' cf. ' $m B$ ' for mid- and late-gastrula); (2) the $\mu \mathrm{BOD}$ measurements $(\mu \mathrm{B}, \mathrm{Fig}, 6)$ were not different from the Winkler and $\mathrm{mBOD}$ measurements; (3) the continuous measurements by coulometric respirometry (CCR tracings, Fig. 6) showed the temporal variation in respiration rates not evident in end-point determinations, and the range of values from the coulometric measurements fell within the end-point rates determined by Winkler's titration and by the mBOD and $\mu B O D$ methods; (4) the continuous POS measurements of oxygen with developing animals inside the micro-respiration chambers were between 57 and $74 \%$ less than those determined by the other end-point methods (statistics: morulae $=t$-test of $\mu B O D$ and POS, $\mathrm{p}<0.022$; both mid- and late-gastrulae = ANOVA with Tukey's at $p<0.05$; prism = non-parametric Kruskal-Wallis Rank ANOVA with Dunn's com- 

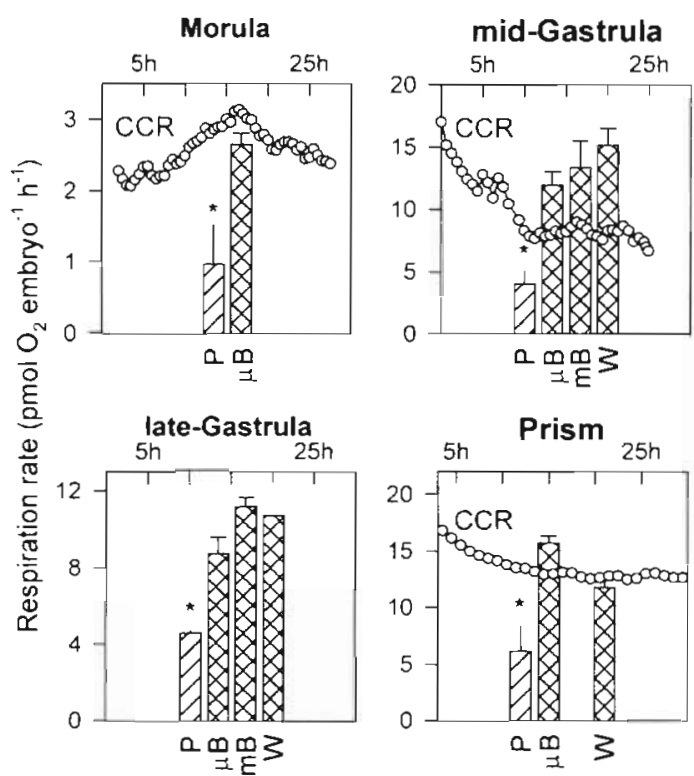

Fig. 6. Respiration rates at $-1.5^{\circ} \mathrm{C}$ of the Antarctic sea urchin Sterechinus neumayeri for $2 \mathrm{~d}$ old morula, $10 \mathrm{~d}$ old midgastrula, $15 \mathrm{~d}$ old late-gastrula and $19 \mathrm{~d}$ old prism stage of development. Respiration rates were measured by 5 different methods (as in Fig. 5), but not all methods were used on all stages. CCR: coulometric capacitance respirometry with the continuous measurements plotted on the upper $x$-axis in intervals of $5 h_{i} P$ : continuous detection of respiration rate by a polarographic oxygen sensor in a $100 \mu \mathrm{l}$ micro-respiration chamber $(n=2) ; \mu \mathrm{B}$ : end-point determination of oxygen in a series of small $(<1 \mathrm{ml})$ BOD vials $(n=3)$; $m B$ : end-point detection by POS of oxygen in a series of large $(300 \mathrm{ml}) \mathrm{BOD}$ bottles $(\mathrm{n}=3) ; \mathrm{W}$ : direct chemical titration of dissolved oxygen in a series of large $(300 \mathrm{ml})$ BOD bottles $(n=3$; same ones subsampled for ' $m B O D$ ' above). Histograms are plotted as means $\pm 1 \mathrm{SE}$, except for the POS data where the uncapped vertical line represents the maximum value of the 2 replicate mesurements. Bars with the same shading are not statistically different; $_{i}$ i.e. POS is different at $p<0.05$ (") from $\mu \mathrm{BOD}, \mathrm{mBOD}$ and Winkler. Where an error bar is not visible for a Winkler analysis, it falls within the graphical representation of the histogram

parison at $p<0.05$ using $\mu B O D$ as the comparative control). In summary, these findings show that the $\mu B O D$ method was as accurate as both the Winkler's titration of $\mathrm{BOD}$ bottles and as the coulometric respiro. meter. The continuous measurement of respiration by the POS in micro-respiration chambers provided the least accurate data when compared to all the other methods.

The difference in respiration rates measured by the $\mu B O D$ method and the continuous measurement of respiration by a POS in a micro-respiration chamber were substantial and illustrate the importance of verifying the accuracy of any method for measuring respiration rates. The discrepancy between $\mu B O D$ and POS was further investigated by calculating the total metabolic requirements during early development of Sterechinus neumayeri using these 2 methods on each of 3 independent cultures (Fig. 7). From fertilization to gastrulation $\left(12 \mathrm{~d}\right.$ at $\left.-1.5^{\circ} \mathrm{C}\right)$, the 2 methods yielded estimates of the metabolic costs of embryogenesis that differed by 2.7 -fold (calculated from the cumulative oxygen consumed during development). When measured by the $\mu B O D$ method, the cumulative respiration over the first $12 \mathrm{~d}$ of development totaled $1.90 \mathrm{nmol} \mathrm{O}_{2}$ $( \pm 0.06 \mathrm{SE}, \mathrm{n}=3$ cultures). Simultaneous measurements made with the POS/micro-respiration chamber totaled only $0.71 \mathrm{nmol} \mathrm{O}_{2}( \pm 0.01 \mathrm{SE}, \mathrm{n}=3$ cultures $)$. The increase in the respiration rate during embryogenesis presumably results from the increase in cell numbers during development.

\section{DISCUSSION}

The most important factor to consider in measuring respiration rates is the accuracy of the method employed. POS placed in micro-respiration chambers has been the method of choice used by many investigators for measuring respiration during development in many species of marine invertebrates (Gerdes 1983, Manahan 1983, Jaeckle \& Manahan 1989, Shilling \& Manahan 1994, Hoegh-Guldberg \& Emlet 1997). Quantification with the POS unit of oxygen tensions in end-point samples is extremely accurate (Bridges

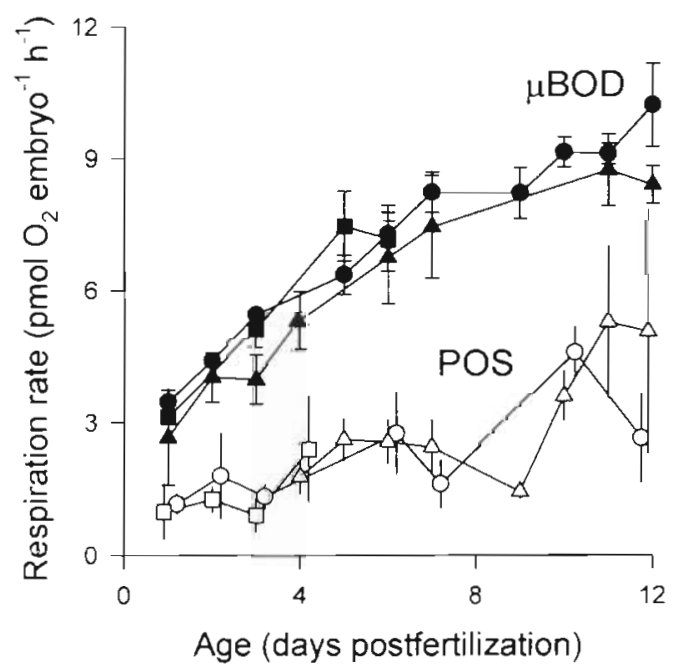

Fig. 7. Respiration rates at $-1.5^{\circ} \mathrm{C}$ during embryonic development to Day 12 (gastrula) for the Antarctic sea urchin Sterechinus neumayeri. Ontogenetic changes in oxygen consumption were determined on cultures from 3 separate spawnings (circles, squares and triangles). Respiration measured by 2 methods: $\mu \mathrm{BOD}$ (solid symbols) = end-point determination of oxygen in a series of small $(<1 \mathrm{ml}) \mathrm{BOD}$ vials (mean $\pm 1 \mathrm{SE}$, $\mathrm{n}=3$ ); POS (open symbols) = continuous detection of respiration rate by a polarographic oxygen sensor in a $1.00 \mu \mathrm{l} \mathrm{micro-}$ respiration chamber (mean plotted with vertical lines indicating the values of the 2 replicate observations) 
1983). However, when the latter method is used for respiration measurements of most embryos and larvae tested, the resulting respiration rates can be underestimated by up to 3 -fold. Although the bases of these lower estimates in POS/micro-respiration chambers is still unknown (see Hoegh-Guldberg \& Manahan [1995] for a discussion of this matter), we have consistently seen this problem using chambers ranging in volume from 50 to $1000 \mathrm{\mu l}$ (Hoegh-Guldberg \& Manahan 1995, Shilling et al. 1996, this study).

Our comparison of several different methods showed that respiration rates of embryos and larvae measured by the $\mu B O D$ method were comparable to those measured by large-scale Winkler's titration and also to those determined by coulometric capacitance respirometry. In marked contrast, continuous measurements of oxygen consumption inside a POS/ micro-respiration chamber underestimated respiration in embryos and larvae of Sterechinus neumayeri by up to $63 \%$ (Fig. 6, morula). If the cumulative oxygen consumption values for both the $\mu$ BOD method and the POS/micro-respiration chambers (from Fig. 7) are converted to energy equivalents $\left(484 \mathrm{~kJ} \mathrm{~mol}^{-1} \mathrm{O}_{2}\right.$ assuming equal use of protein and lipid; Gnaiger 1983), the $\mu B O D$ measurements convert to $920 \mu \mathrm{J}$ utilized during the first $12 \mathrm{~d}$ of development (fertilization to gastrulation). However, based on simultaneous measurements of embryos during the same period of development from the same cultures, respiration data obtained by POS/micro-respiration chambers gave a much lower energy requirement of only $343 \mu \mathrm{J}$. The 2.7 -fold difference between these 2 estimates of energy requirements demonstrates the importance of selecting an appropriate method for accurate measurements of respiration rates.

Using a $\mu \mathrm{BOD}$ vial with a $1 \mathrm{ml}$ volume provided a large enough sample for flushing the detection chamber before each measurement (using a standard Strathkelvin $\mathrm{RC}-200$ respiration chamber set at $75 \mu \mathrm{l}$ ), while still being small enough to detect changes in oxygen concentrations over relatively short incubations ( 4 to $8 \mathrm{~h}$ ). For routine measurements using the $\mu B O D$ method, we recommend working with a range of concentration of animals sufficient to produce a maximum depletion of $10 \%$ (Fig. $2 \mathrm{~A}$, highest point) down to the statistical detection limit (Fig. 2B). The oxygen consumption rate on a per individual basis must also be independent of the concentration of animals used to make respiration measurements. The general lack of a concentration-dependent effect on respiration (Figs. 2 to 4 ) for embryos and larvae within the $\mu B O D$ vials (at $<600$ ind $\mathrm{ml}^{-1}$ ) indicates that this technique is robust and could be used for routine respiration measurements during development of many echinoderm species and other small zooplankton.
The large numbers of replicate measurements that can be easily made with the $\mu \mathrm{BOD}$ method provides a unique statistical advantage over most of the other available methods used to measure respiration rates. From Figs. 2 to 4, we have calculated individual respiration rates as the slope of the regression of total oxygen consumption as a function of the concentration of individuals. This approach partitions some of the measurement error into a $y$-intercept value, thereby removing that error from the rate calculation as estimated from the regression slope.

Theoretically, any regression of total respiration against animal number should have a $y$-intercept of 0 (an untested assumption for many previous studies of larval respiration). If a $y$-intercept is statistically different from 0 , then some oxygen depletion (independent of the number of individuals) was not accurately quantified by the blank controls. In our experience, $y$-intercepts are often significantly different from 0 , despite our use of numerous blanks (usually 1 blank vial for every 4 sample vials). In a data set where there is a significant $y$-intercept, if an individual's respiration rate were simply calculated as the ratio of total respiration to total individuals, then the resulting individual's respiration rate would be incorrect because it would represent the slope of a regression that was forced through the origin (i.e. $y$-intercept $=0$ respiration, at $x=0$ ind.). The approach of using a regression of respiration against individual number does not make any assumptions about the $y$-intercept because in the analyses only the oxygen consumption that is directly proportional to the number of individuals (slope) is used to estimate an individual's respiration rate.

The rate of energy utilization, as measured by respiration, is a critical physiological measurement for studies of metabolic processes that vary during development and as a function of environmental factors. There are several methods currently available that can be used for measuring micro-respiration rates of invertebrate embryos and larvae. However, the most critical aspect of choosing 1 of these methods is that it is first validated for use with the life-stage of the species being studied. We have described here a new approach using $\mu B O D$ vials with POS for end-point detection of $\mathrm{O}_{2}$ concentrations. This method is simple to operate, robust enough for field work, and extremely accurate for micro-respiration measurements of embryos and larvae.

Acknowledgements. We thank P. Leong for help with culturing sea urchins and for performing many of the Winkler's titrations presented here; T. Hamilton for collecting the Antarctic urchins and helping with those cultures; D. Pace and Dr M. Sewell for help with culturing the seastars; Dr A. Huesner for discussions about the design and operation of the coulometric current meter; N. Appelmans for redesign of the coulometric respiration chambers; and Antarctic Support 
Associates Inc for providing all the logistics necessary for our research at McMurdo Station, Antarctica. This work was supported by NSF grants OPP \#94-20803 and OCE \#9619242.

\section{LITERATURE CITED}

Bhatnagar KM, Crisp DJ (1965) The salinity tolerance of nauplius larvae of cirripedes. J Anim Ecol 34:419-428

Bridges CR (1983) $\mathrm{pO}_{2}$ and oxygen content measurement in blood samples using polarographic oxygen sensors. In: Gnaiger E, Forstner H (eds) Polarographic oxygen sensors, aquatic and physiological applications. Springer Verlag. New York, p 219-233

Crisp DJ (1974) Energy relations of marine invertebrate larvae. Thal Jugoslav 10:103-120

Gerdes D (1983) The Pacific oyster Crassostrea gigas Part II. Oxygen consumption of larvae and adults. Aquaculture $31: 221-231$

Gnaiger E (1983) Calculation of energetic and biochemical equivalents of respiratory oxygen consumption. In: Gnaiger E, Forstner $\mathrm{H}$ (eds) Polarographic oxygen sensors, aquatic and physiological applications. Springer Verlag, New York, p $337-345$

Hoegh-Guldberg O, Emlet R (1977) Energy use during development of a lecithotrophic and a planktotrophic Echinoid. Biol Bull 192:27-40

Hoegh-Guldberg O, Manahan DT (1995) Coulometric measurement of oxygen consumption during development of marine invertebrate embryos and larvae. J Exp Biol 198: $19-30$

Editorial responsibility: William B. Stickle $J_{r}$. (Contributing Editor), Baton Rouge, Louisiana, USA
Huesner AA, Tracy ML (1984) Coulometric measurement of oxygen consumption in insects. In: Bradley TJ, Miller TA (eds) Measurement of ion transport and metabolic rates in insects. Springer Verlag, New York, p 163-186

Huesner AA, Hurley JP, Arbogast R (1982) Coulometric microrespirometry. Am J Physiology 243:R185-R192

Jaeckle WB, Manahan DT (1989) Growth and energy imbalance during development of the lecithotrophic molluscan larva Haliotis rufescens. Biol Bull 177:237-246

Manahan DT (1983) The uptake and metabolism of dissolved amino acids by bivalve larvae. Biol Bull 164:236-250

Meyer H (1935) Die Atmung von Asterias rubens und ihre Abhängigkeit von verschiedenen Außenfaktoren. Zool Jahrb Allg Zool Physiol 55:349-398

Parsons TR, Maita Y, Lalli CA (1984) A manual of chemical and biological methods for seawater analysis. Pergamon Press, Oxford

Scholander PF, Claff CL, Sveinsson SL, Scholander. SI (1952) Respiratory studies of single cells. III Oxygen consumption during cell division. Biol Bull 1.02:185-199

Shilling FM, Manahan DT (1994) Energy metabolism and amino acid transport during early development of Antarctic and temperate echinoderms. Biol Bull 187: $398-407$

Shilling FM, Hoegh-Guldberg O. Manahan DT (1996) Sources of energy for increased metabolic demand during metamorphosis of the abalone Haliotus rufescens (MolIusca). Biol Bull 191:402-412

Zeuthen E (1943) A Cartesian Diver micro respirometer with a gas volume of $0.1 \mathrm{ml}$. CRT Lab Carlsberg, Ser Chim 24: $479-518$

Submitted: February 27, 1998; Accepted: January 7, 1999; Proofs received from author(s): July 2, 1999 